\title{
TP53 Protein Variant
}

National Cancer Institute

\section{Source}

National Cancer Institute. TP53 Protein Variant. NCI Thesaurus. Code C146884.

A variation in the amino acid sequence for cellular tumor antigen p53. 